\title{
Erratum to: Reply to the commentary by Dr. Sauerland S. and Dr. Gross CTR
}

\author{
Gianlorenzo Dionigi
}

Published online: 14 February 2013

(C) Springer-Verlag Berlin Heidelberg 2013

Erratum to: Langenbecks Arch Surg

DOI 10.1007/s00423-012-1014-9

The original article has been published with an unauthorized and misleading change in the list of authors: M.W. Büchler, M. Schneider, S. Sauerland and C.T. Gross did not author this article.

The corrected version of the author group and affiliation sections can be seen above and below.

The online version of the original article can be found at http://dx.doi.org/ 10.1007/s00423-012-1014-9.

G. Dionigi $(\bowtie)$

Surgery, University of Insubria,

Varese, Italy

e-mail: gianlorenzo.dionigi@uninsubria.it 